\title{
Hanta hemorrhagic fever with renal syndrome: A pathology in whose diagnosis kidney biopsy plays a major role (Review)
}

\author{
GABRIELA LUPUŞORU ${ }^{1,2}$, MIRCEA LUPUŞORU ${ }^{3}$, IOANA AILINCĂI $^{1}$, LAVINIA BERNEA ${ }^{1}$, \\ ANDREEA BERECHET ${ }^{1}$, RADU SPĂTARU ${ }^{4}$ and GENER ISMAIL ${ }^{1,2}$ \\ ${ }^{1}$ Department of Nephrology, 'Fundeni' Clinical Institute, 022328 Bucharest; Departments of ${ }^{2}$ Uronephrology, \\ ${ }^{3}$ Physiology I and ${ }^{4}$ Pediatric Surgery, 'Carol Davila' University of Medicine and Pharmacy, 020021 Bucharest, Romania
}

Received March 15, 2021; Accepted April 14, 2021

DOI: $10.3892 /$ etm.2021.10416

\begin{abstract}
Hantavirus infection belongs to a group of zoonoses rare in the Balkan Peninsula, causing two major syndromes, depending on the viral serotype involved: Hemorrhagic fever with renal syndrome (HFRS) also known as endemic nephropathy and cardiopulmonary syndrome (CPS). Because there is no specific treatment or vaccine for this condition approved in the USA or Europe, the key to minimizing the risk of adverse progression to chronic kidney disease, secondary hypertension or even death is primarily the recognition and early diagnosis of this condition with prompt therapeutic intervention. The aim of this study was to review the literature data on the epidemiology, pathogenesis and management of this disease and to identify several aspects related to the difficulties encountered in diagnosing this pathology, taking into consideration that the disease is not endemic in this geographical area.
\end{abstract}

\section{Contents}

1. Introduction

2. Epidemiology

3. Pathogenesis

4. Pathological findings

5. Clinical manifestations

6. Diagnosis and treatment

7. Conclusions

Correspondence to: Dr Mircea Lupuşoru, Department of Physiology I, 'Carol Davila' University of Medicine and Pharmacy, 37 Dionisie Lupu Street, 020021 Bucharest, Romania

E-mail: mircealupusoru@yahoo.com

Key words: hantavirus, hemorrhagic fever with renal syndrome, acute renal injury, endemic nephropathy, interstitial hemorrhage

\section{Introduction}

The hantavirus infection is part of a rare group of zoonoses with increasing frequency and geographic spread in the last years. The Hantavirus genus includes various human pathogenic serotypes, whose hosts are mainly wild rodents (1). Hantaviruses are classified in two large groups, according to their geographic distribution: The Old World hantaviruses and The New World hantaviruses (1). The Old World hantaviruses cause hemorrhagic fever with renal syndrome (HFRS), while the New World hantaviruses are associated with hantavirus cardiopulmonary syndrome (CPS) (1).

Onset of HFRS is similar to a flu-like syndrome, with fever and prospects to evolve into an acute kidney injury (AKI) with severe thrombocytopenia, anemia and coagulation dysfunction (2), mimicking the thrombotic microangiopathy (TMA) from the hemolytic uremic syndrome (HUS), with which it is frequently confused. The renal dysfunction is manifested through decrease in the glomerular filtration rate, hematuria and transient proteinuria, often in the nephrotic range, which indicates a lesion of the glomerular filtration barrier (2). The typical histological aspect is that of an acute tubulointerstitial nephritis with hemorrhage in the outer medulla, but glomerular endothelial lesions are also present (3).

This review emphasizes the importance of the renal biopsy in the diagnosis of hantavirus hemorrhagic nephritis and draws attention on this zoonosis that may be highly underdiagnosed in the Balkan Peninsula.

\section{Epidemiology}

Hantavirus infection belongs to a group of rare zoonotic diseases but with increasing incidence and geographical range in the last years. The genus Hantavirus is a member of the Bunyaviridae family and includes over 28 serotypes that cause infections in humans, rodents being regarded as the main reservoir for the pathogen. Hantaviruses have a diameter of 80-120 $\mathrm{nm}$ and are enveloped viruses; the lipoprotein envelope being easily inactivated by disinfectants. They are characterized by a negative-sensed trisegmented single-stranded RNA genome (2). The envelope has glycoprotein projections with hemagglutinin activity (Gn and Gc). The genome comprises three segments (small, S; medium, M; and large, L) coding the 
viral nucleocapsid protein $(\mathrm{N})$, two envelope glycoproteins and the genome associated RNA-dependent RNA-polymerase (4). The viruses replicate within the cytoplasm of the infected cells and are released in the bloodstream by virus budding.

The history of hantaviruses initiated between 1951 and 1953, during the Korean war, when the first cases of hemorrhagic fever (Korean hemorrhagic fever) were reported in an area along the Hantaan River, after which they were named (1). The virus was isolated in 1978 by Ho Wang Lee from lung tissue belonging to the striped field mouse Apodemus agrarius that was experimentally inoculated with the pathogen of the Korean hemorrhagic fever (5). Hantaviruses are spread worldwide in endemic areas and their classification is performed according to the geographical distribution: The Old World hantaviruses which cause HFRS and The New World hantaviruses which cause CPS; these diseases are responsible for the hospitalization of 150.000-200.000 individuals worldwide each year $(2,6)$. Within the Old World hantaviruses, which are usually found in Europe and Asia, the best known species are Puumala orthohantavirus (PUUV), Hantaan orthohantavirus (HTNV), Seoul orthohantavirus (SEOV) and Dobrava-Belgrade orthohantavirus (DOBV), the latter being spread mostly in the Balkan Peninsula, but also the Saaremaa virus (SAAV) which is genetically related to DOBV, and the Tula virus (TULV) (2). DOBV, the most prevalent serotype observed in the Balkan Peninsula, is responsible for a $12 \%$ mortality rate associated with infection (7). There are four rodent species constituting the virus host: Apodemus, Microtus, Myodes and Rattus; the rodents do not develop the disease, but their growth may be affected as a consequence of the infection $(8,9)$ and they can also spread the virus to other animals: Moose, red fox, bat, domestic cat and dog (10-13). The New World hantaviruses are found in America; the best known are Sin Nombre virus and Andes virus, the latter being the only Hantavirus for which person-to-person transmission may take place $(14,15)$.

The European Center for Disease Prevention and Control published a list with 29 countries reporting 1,826 cases of hantavirus infection for the year 2018, with most of the cases (97\%) involving PUUV (16). However, there is the possibility that most HFRS cases, being mild and moderate forms of disease, are underdiagnosed and thus, the incidence of the disease in Europe may be underestimated. The Dobrava strain was confirmed as the causative agent in endemic nephropathy cases in Central and South Eastern Europe (17).

Humans do not belong to the natural host range of hantaviruses and infection generally occurs by inhalation of virus-containing aerosols from rodent faeces, urine and saliva, but also by rodent bite and skin lesions $(18,19)$. People at increased risk of infection are those who live or work in rural areas and come into close contact with virus reservoirs: Forestry workers, farmers, hunters, and military personnel (who can be easily infected during military exercises) (2). The existence of a genetic susceptibility involved in the pathogenesis of the disease was recently revealed: The HLA-B8 DR3 and DQ2 haplotypes are associated with a severe clinical course of the infection, while HLA-B27 is associated with a benign clinical course of the infection (20-23). There are two peaks of incidence over the course of one year: The first peak is in August, during the vacation season that starts in July, and the second peak is in November and December when the onset of cold weather causes mice to search for shelter in people's homes (24).

\section{Pathogenesis}

In patients with endemic nephropathy, hantaviruses infect renal endothelial cells, podocytes and tubular epithelial cells. The pathogenesis of the infection is complex and not yet fully understood and it is characterized by endothelial damage with enhanced capillary permeability, disruption of tight junctions of tubular epithelial cells and alterations of the podocyte cytoskeleton (25-29).

Endothelial integrity is the result of a complex interaction between endothelial cells, thrombocytes and immune cells (29).

Hantaviruses infect the susceptible cells (endothelial cells, tubular epithelial cells and glomerular cells) by interaction of the viral envelope glycoproteins ( $\mathrm{Gn}$ and $\mathrm{Gc}$ ) with $\beta$-integrin surface molecules. Both pathogenic and nonpathogenic hantavirus strains infect the human cells, but the receptors they use for cellular entry are different: $\alpha v \beta 1$ and $\alpha v \beta 3$, respectively (26); these surface receptors, usually involved in matrix adhesion, are being blocked in the process of virus attachment. Thus, the virus affects the renal tubular epithelium, the podocytes and the capillary endothelial cells by disturbing the integrity of cell-to-cell contacts and also by stimulating the immune system. Evidence has revealed that immature dendritic cells are involved in the dissemination of hantaviruses, as they express on their surface the $\alpha v \beta 3$ integrin and can be found in the proximity of epithelial cells (30). Hantavirus-infected dendritic cells help spread the virus by migrating through lymphatic vessels to the regional lymph nodes and then to the endothelial cells (31), as they exert their role of antigen-presenting cells and induce the immune activation of $\mathrm{T}$ lymphocytes. High levels of cytotoxic $\mathrm{CD} 8^{+} \mathrm{T}$ lymphocytes were detected in the serum of patients with HFRS and the evidence revealed that the endothelial damage was not caused by direct cellular cytotoxicity of the hantavirus, but by pro-inflammatory cytokines produced by the virus-specific $\mathrm{T}$ lymphocytes that attack the endothelial cells expressing viral antigens on their surface (32), thus contributing to the capillary leakage. Infection of the endothelial cells initiates an inflammatory response involving the activation of the complement system and the release of pro-inflammatory cytokines such as TGF, interferons, interleukins (IL-6 and IL-10) and TNF (33). Increased levels of IFN $\gamma, \mathrm{IL}-10$ and TNF $\alpha$ were revealed in the serum of patients with PUUV and DOBV and also in patients with severe clinical course of disease (34). Several signaling cascades that use vascular endothelial growth factor (VEGF), IL-6 or urokinase plasminogen activator receptor (UPAR) as mediators have been described to be involved in the regulation of podocyte function; these mediators are also known to be upregulated in endemic nephropathy (35), thus supporting the involvement of podocyte alteration in the hantavirus infection pathogenesis.

\section{Pathological findings}

The most frequent pattern of injury observed in HFRS kidney biopsy specimens is acute tubulointerstitial nephritis (3). 
A

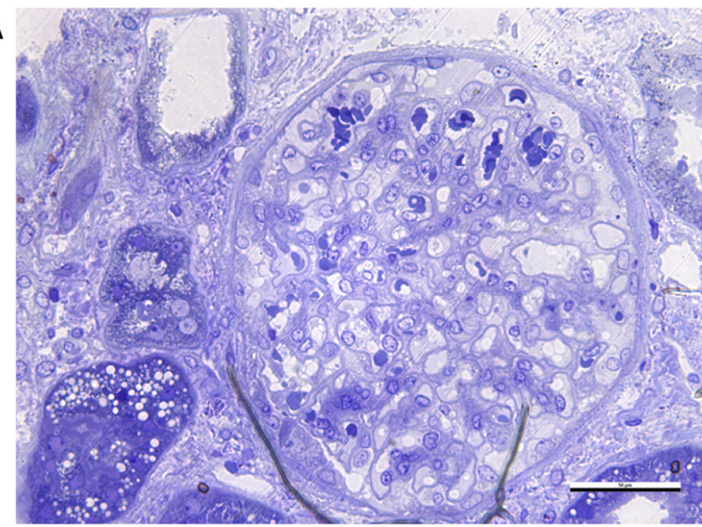

C

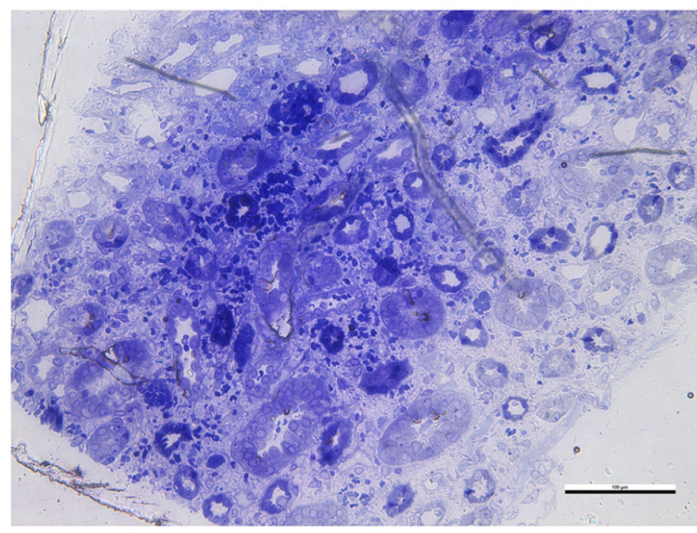

E

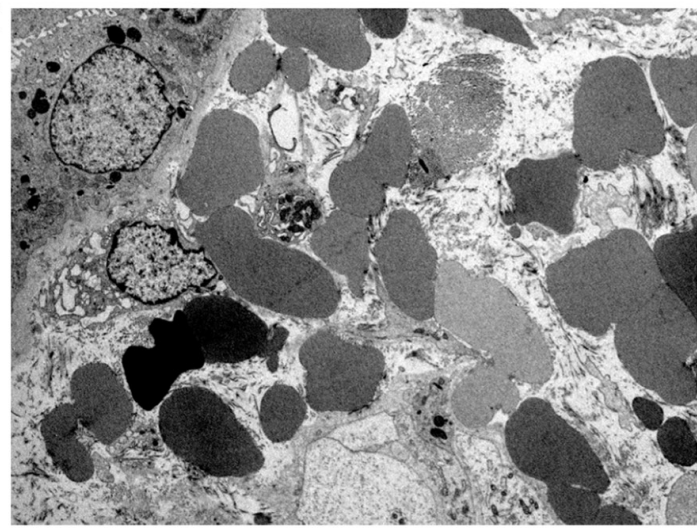

B

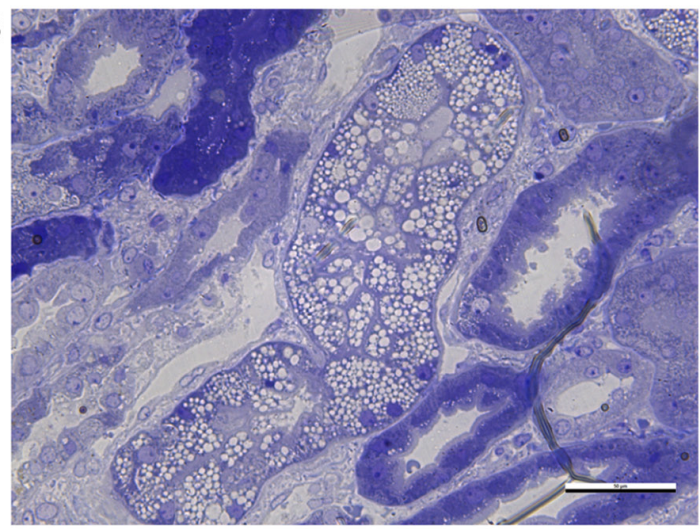

D

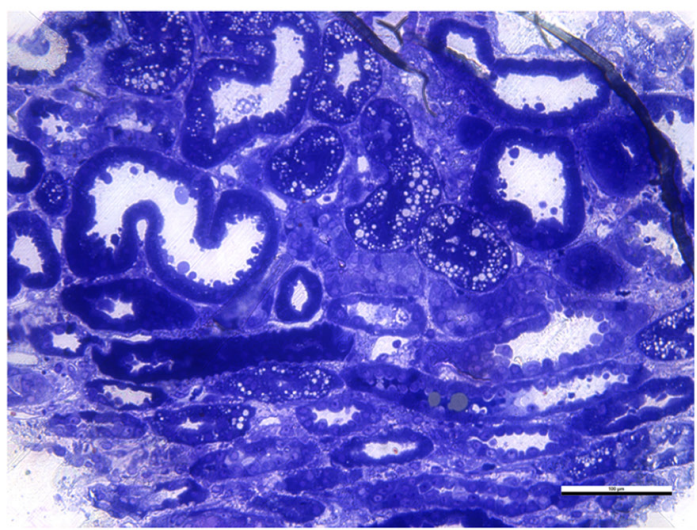

F

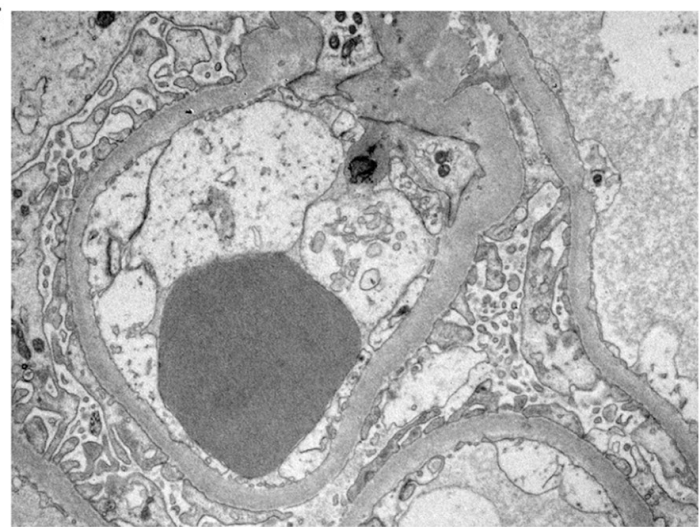

Figure 1. Needle biopsy revealing histomorphologic changes in the kidney of a patient with hantavirus infection. (A and B) Light microscopy and toluidine blue staining (x400). Glomeruli with normal appearance. Resorption droplets in the proximal tubular cells. (C and D) Light microscopy and toluidine blue staining (x200). Extensive interstitial hemorrhage in medulla and tubulitis. (E) Electron microscopy (x5,000). Extravasation of erythrocytes into the interstitium. (F) Electron microscopy $(\mathrm{x} 10,000)$. Glomerular capillaries exhibited endothelial swelling with reduced fenestrations and foot process effacement. (Images were obtained from the collection of the Nephrology Department of Fundeni Clinical Institute, Bucharest, Romania).

The kidney biopsy performed in the acute phase of the disease course can raise the suspicion of hantavirus infection immediately after removal of tissue, as it reveals macroscopic features of hemorrhage in the renal medulla (3).

Light microscopy (LM) can reveal normal glomeruli or glomeruli with increased mesangial cellularity. A few studies have described cases of mesangiocapillary glomerulonephritis in hantavirus infection $(3,36)$. The pathognomonic histopathological finding is the interstitial hemorrhage (with both isomorphic and dysmorphic erythrocytes), most commonly found in the outer medulla, that can compress the renal tubules (Fig. 1). The interstitial hemorrhage is present in $20-60 \%$ of the kidney biopsy specimens in the acute phase of hantavirus infection (17). LM also reveals interstitial and periglomerular lymphoplasmacytic cell infiltrates, tubulitis and arterial endothelial swelling.

In immunofluorescence (IF), the staining is usually negative, but a few studies have described mild granular Clq, C3, IgG and IgM deposits along the glomerular capillary walls, thus supporting the theory of classical complement pathway activation in hantaviral infection (11,36-38).

Electron microscopy (EM) can reveal diffuse foot process effacement, denudation of the tubular epithelial cells, resorption droplets in the tubules (in cases of high levels of 24-h proteinuria) and endothelial swelling in the glomerular or peritubular capillaries (Fig. 1); the infected cells can display 
hypertrophy of the Golgi apparatus (3). The foot process effacement and detachment of podocytes from the glomerular basement membranes explains the nephrotic range proteinuria observed in some cases of AKI and strengthens the role of podocyte cytoskeletal alterations in the pathogenicity of $\operatorname{HSRF}(27,28,39)$.

\section{Clinical manifestations}

Hantavirus infection causes two types of clinical syndromes in humans: HFRS and CPS; the difference consisting in the implicated strains and the affected vascular circulation: Capillaries from renal medulla and pulmonary capillaries, respectively. The common lesion is the increased capillary permeability and both forms of disease begin with fever syndrome and flu-like symptoms and have in common thrombocytopenia, left-shifted leukocytosis and arterial hypotension $(1,2,29)$. In the following sections, detailed aspects of HFRS, also known as endemic nephropathy, are presented. Clinical presentation can range from mild to severe forms of disease, depending on the causing strain. Therefore, strains such as HTNV and DOBV can cause severe forms of disease with mortality ranging from 5 to $15 \%$ and strains such as SEOV, PUUV and SAAV in general cause moderate or mild forms of disease with a mortality below $1 \%$ (18). The disease evolution has five chronological phases including:

i) Febrile phase. After an incubation period of 2-4 weeks, the disease begins with flu-like syndrome including high grade fever, myalgia, low back pain, headache, abdominal pain, nausea and vomiting. At this stage most clinicians will first look for a cause of the fever and the following basic laboratory tests will be necessary: Erythrocyte sedimentation rate or $\mathrm{C}$ reactive protein, hemoglobin, platelet count and differential, electrolytes, creatinine, abdominal ultrasonography and other imaging studies (40). This phase lasts 3-7 days and it can be accompanied by ophthalmological disorder; in PUUV infection, a decrease of intraocular pressure was reported in $88 \%$ of the cases, myopia in $78 \%$ of the cases and visual acuity reduction in $87 \%$ (41).

ii) Hypotensive phase. This phase lasts between a few hours and 2 days. It can appear as severe arterial hypotension and irreversible shock. This is the phase when thrombocytopenia, leukocytosis, haemorrhagic manifestations such as skin and mucous petechiae, hematemesis, epistaxis, melena, hematuria or even intracerebral haemorrhage appear; in addition, the production of urine decreases in this phase.

iii) Oliguric phase. The duration of this phase is between 3 and 7 days and it can be accompanied by abdominal or low back pain. Glomerular filtration rate diminishes and oliguria or even anuria appear, nitrogen waste products increase and microscopic hematuria and proteinuria occur. This is the phase when arterial hypotension disappears and patients can even develop arterial hypertension through hydrosaline retention.

iv) Polyuric phase. The duration of this phase ranges from a few days to a few weeks. The recovery of renal function begins and diuresis increases to a few liters per day, thus, important hydroelectrolytic disorders may occur.

v) Convalescence. This phase lasts from 2 to 6 months. This is the period when renal function and laboratory abnormalities are completely recovering; however, there are cases which can develop long-term complications and persistent complications such as arterial hypertension and chronic kidney disease (42-44).

The most frequent laboratory abnormalities are thrombocytopenia, leukocytosis, increase of C-reactive protein, increase of creatinine, proteinuria and hematuria. Increased levels of procalcitonin, IFN $\gamma$, TNF $\alpha$ and IL-10, especially in patients with DOBV infection have also been revealed $(34,45)$. In PUUV infection, IL-6 serum level has been revealed to be correlated with thrombocytopenia and severity of renal function damage and it is used as a disease severity marker (46); the urinary level of IL- 6 has been demonstrated to be correlated with proteinuria, suggesting local production of this cytokine (47).

It is already recognized that alternative pathway complement activation contributes to pathogenesis of PUUV infection $(48,49)$ and there is evidence that increased serum levels of the C5b-C9 complex and reduced C3 level from acute phases appear, especially in patients with pulmonary radiologic abnormalities (24).

Thrombocytopenia is recognized as a severity marker of hantavirus infection (46) and is caused by peripheral consumption related to endothelial activation $(24,50)$. It has been demonstrated that platelet adhesion to infected endothelial cells is directed by hantavirus pathogenic strains through $\beta 3$ integrin receptor (25). This results in alteration of platelet activation with reduction of their count and loss of vascular integrity, so that the endothelial lesions may promote coagulation activation and fibrinolysis, effects observed through increased prothrombin and D-dimers (50). Literature data has revealed that platelet count is a predictor of severity and progression of disease $(51,52)$.

Most frequently the recovery of hantavirus infection is complete, but there are cases which evolve with acute or chronic complications. The majority of the acute complications that can be life-threatening are caused by hydroelectrolytic disorders, shock with ischemia, haemorrhage or necrosis (24). Thus, in PUUV and DOBV strain infections, pituitary gland haemorrhage and necrosis, meningoencephalitis, AKI with renal replacement therapy, pulmonary edema, pericarditis, myocarditis, disseminated intravascular coagulation have been observed (6,53-66) (Table I).

Arterial hypotension is one of the most common acute complications of HFRS, being caused by dehydration secondary to nausea and vomiting and by vascular injury from complement activation $(33,48,49)$, thrombocytes $(24,46,50)$ and immune effector cell activation that synthetize vasoactive mediators, interleukins and TNF. Patients can also develop arterial hypertension based on decreased glomerular filtration rate in the oliguric phase of disease, but also on capillary leak phenomenon with high protein extravasation to third space leading to weight gain (revealed by severe hypoalbuminemia), acute pulmonary edema and renal interstitial edema. 
Table I. Acute complications of hantavirus infection [adapted from Vaheri et al (24)].

Acute complications in hantavirus infection with PUUV and DOBV serotypes

Renal

Acute kidney injury and renal replacement therapy

required $(53,54)$

Cardiopulmonary

Pulmonary edema (55)

Arterial hypotension and shock (6)

Pericarditis, myocarditis (56)

Neurological

Meningoencephalitis $(57,58)$

Seizures (59)

Pituitary haemorrhage (60)

Guillain-Barre syndrome (61)

Neurogenic bladder and hemiparesis $(62,63)$

Hematological

Disseminated intravascular coagulation (50)

Digestive

Pancreatitis $(64,65)$

Others

Multiple organ dysfunction syndrome (66)

PUUV, Puumala virus; DOBV, Dobrava virus.

Table II. Chronic complications of Hantavirus infection [adapted from Vaheri et al (24)].

Chronic complications of hantavirus infection

Renal

Chronic tubulointerstitial nephritis (67)

Membranoproliferative glomerulonephritis $(36,68)$

Cardiovascular

Arterial hypertension (69)

Endocrine

Testicular insufficiency (70)

Hypopituitarism (70)

Hypothyroidism $(71,72)$

The most frequent chronic complications of hantavirus infection are hormone deficiency (hypopituitarism and hypothyroidism) and tubulointerstitial nephritis with tubular proteinuria developed after years from infection, as well as membranoproliferative glomerulonephritis and arterial hypertension (67-72) (Table II).

One of the proposed mechanisms for arterial hypertension in hantavirus infection is the renal microvascular impairment along with significant tubulointerstitial inflammation. Every factor inducing vasoconstriction in renal medulla and the adjacent cortex can cause arterial hypertension. Hantavirus infection constitutes an initiating factor for renal vasoconstriction, a theory supported by the histological appearance with congestion and haemorrhage around the vessels in the outer medulla and corticomedullary junction and also by the endothelial injury (73).

\section{Diagnosis and treatment}

Diagnosis is performed based on epidemiological, clinical and laboratory findings. However, it has to be suspected whenever a patient presents with fever, headache, abdominal or low back pain, AKI and thrombocytopenia and confirmed with serological testing. At hospitalization, patients usually already have IgM and IgG anti-hantavirus antibodies because they become positive along with the occurrence of symptoms. The most commonly used method of serological detection of antibodies is by indirect ELISA for IgM and IgG, however indirect IF and rapid immunochromatographic tests are also used. Hantavirus infection can also be revealed through detection of the viral genome from the serum of patients using RT-PCR and the level of viremia has been revealed to be correlated with disease severity (74-77). Due to the specificity of interstitial hemorrhage on the kidney biopsy specimens of patients with HFRS as well as the frequency of chronic tubulointerstitial nephritis as a complication of this pathology, a kidney biopsy should be considered as a diagnostic tool. It is important to estimate the risk/benefit ratio of kidney biosy in these patients, as thrombocytopenia associated to HFSR increases the risk of bleeding. Careful attention should be paid to the medical history of patients regarding the treatments that could interfere with the level of thrombocytes and coagulation tests such as oral anticoagulation (OA) recognizing that both traditional OA and new oral anticoagulants are used at an increasing scale (78).

Considering that the hantavirus typically causes a self-limiting infection and it resolves in 2-3 weeks, treatment is mainly supportive. Occasionally renal replacement therapy is required (in $<5 \%$ of the cases) $(24,79)$ and this is mostly due to hypervolemia. Thus, an effective option of supportive treatment is the proper monitoring of hydroelectrolytic balance and avoidance of fluid retention, especially for patients with anuria (2). Platelet transfusions may be provided in cases of severe thrombocytopenia with bleeding risk $(2,43)$.

Among the antiviral drugs, anti-hantavirus activity was demonstrated with ribavirin in vitro and in vivo and there are several Chinese studies on patients with HFRS that exhibited an important reduction of mortality and morbidity when it was administered in the first 5 days after appearance of symptoms $(80,81)$. Another study revealed that early intravenous administration of ribavirin in HFRS reduced the severity of AKI and the occurrence of oliguria (82).

Treatment with icatibant, an antagonist of bradykinin B2 receptor, may be beneficial in severe forms of HFRS with important capillary leakage phenomenon $(83,84)$ due to the role of bradykinin in vascular permeability.

Corticosteroids are not part of the routine viral infection therapy, however, considering the damage of the hantavirus on endothelial cells and the cytokine storm with increased capillary permeability, it appears that methylprednisolone has beneficial effects on the pathogenesis of the disease, 
controlling the immune response. A retrospective study from Chile that included 22 patients with CPS treated with high-dose methylprednisolone demonstrated its efficacy in decreasing mortality (85), and therefore this treatment was implemented for hantavirus infection in various medical centers (86). Conversely, there are phase 2 studies that tested the safety and efficacy of intravenous administration of methylprednisolone which did not demonstrate favorable effects (86), therefore treating hantavirus infection with corticosteroids depends on the decision of the clinician.

\section{Conclusions}

Hantavirus endemic nephropathy belongs to a group of rare zoonoses in the Balkan Peninsula and the most frequently involved serotypes are Dobrava and Puumala. The disease begins with flu-like symptoms such as fever and progresses to AKI with severe thrombocytopenia, anemia and coagulation disorders, symptoms similar to microangiopathy in hemolytic uremic syndrome with which it may often be confused. In a geographic region with only sporadic cases, multiple diagnostic difficulties are encountered, especially related to the absence of initial diagnosis suspicion. Therefore, the need to include this pathology in the algorithm of differential diagnosis of pathologies associated with thrombocytopenia, anemia, hepatic cytolysis syndrome and renal injury, is emphasized.

\section{Acknowledgements}

Not applicable.

\section{Funding}

No funding was received.

\section{Availability of data and materials}

Not applicable.

\section{Authors' contributions}

GL, ML, IA, LB, AB, RS and GI contributed to the conception, writing, review and editing of the manuscript. ML was responsible for methodology. RS, ML and IA were responsible for resources; GL and IA contributed to the data curation. GL, ML, IA and GI contributed to writing of the original draft. GI supervised the study. All authors have read and approved the final version of the manuscript to be published.

\section{Ethics approval and consent to participate}

Not applicable.

\section{Patient consent for publication}

Not applicable.

\section{Competing interests}

The authors declare that they have no competing interests.

\section{References}

1. Zeier M, Handermann M, Bahr U, Rensch B, Muller S, Kehm R, Muranyi W and Darai G: New ecological aspects of hantavirus infection: A change of A paradigm and a challenge of prevention-a review. Virus Genes 30: 157-180, 2005.

2. Avšič-Županc T, Saksida A and Korva M: Hantavirus infections. Clin Microbiol Infect 21S: e6-e16, 2019.

3. Satoskar A, Nadasdy T and Silva F: Acute postinfectious glomerulonephritis and glomerulonephritis caused by persistent bacterial infection. In Heptinstall's Pathology of the Kidney, 7th edition. Jannette JG, Olson JL, Silva FG and D'Agati VD (eds). Lippincott Williams and Wilkins, Philadelphia, pp678-798, 2015.

4. van Regenmortel MHV, Fauquet CM, Bishop DHL, Carstens EB, Estes MK, Lemon SM, Maniloff J, Mayo MA, McGeoch DJ, Pringle CR and Wickner RB (eds): Virus Taxonomy. Seventh Report of the International Committee on Taxonomy of Viruses. 1st edition. Academic Press, San Diego, San Francisco, New York, Boston, London, Sydney, Tokyo, 2000.

5. Lee HW, Lee PW and Johnson KM: Isolation of the etiologic agent of Korean hemorrhagic fever. J Infect Dis 137: 298-308, 1978.

6. Vapalahti O, Mustonen J, Lundqvist Å, Henttonen H, Plyusnin A and Vaheri A: Hantavirus infections in Europe. Lancet Infect Dis 3: 653-661, 2003.

7. Avsic-Zupanc T, Petrovec M, Furlan P, Kaps R, Elgh F and Lundkvist A: Hemorrhagic fever with renal syndrome in the Dolenjska region of Slovenia-a 10-year survey. Clin Infect Dis 28: 860-865, 1999.

8. Steer A: Pathogenesis of renal changes in epidemic hemorrhagic fever. In: The Kidney. IAP Monograph. Mostofi FK and Smith DE (eds). Williams \& Wilkins, Baltimore, pp476-486, 1996.

9. Jokinen EJ, Lähdevirta J and Collan Y: Nephropathia epidemica: Immunohistochemical study of pathogenesis. Clin Nephrol 9: $1-5,1978$

10. Zaki SR, Greer PW, Coffield LM, Goldsmith CS, Nolte KB, Foucar K, Feddersen RM, ZumvaltRE, Miller GL, Khan AS, et al: Hantavirus pulmonary syndrome: Pathogenesis of an emerging infectious disease. Am J Pathol 146: 552-579, 1995.

11. Kim S, Kang ET, Kim YG, Han JS, Lee JS, Kim JI, Hall WC, Dalrymple JM and Peters CJ: Localization of Hantaan viral envelope glycoproteins by monoclonal antibodies in renal tissues from patients with Korean hemorrhagic fever H. Am J Clin Pathol 100: 398-403, 1993.

12. Groen J, Bruijn JA, Gerding MN, Jordans JG, Moll van Charante AW and Osterhaus AD: Hantavirus antigen detection in kidney biopsies from patients with nephropathia epidemica. Clin Nephrol 46: 379-383, 1996.

13. Poljak M and Avšič Županc T: Immunohistochemical detection of Hantaan virus antigen in renal tissue from patient with hemorrhagic fever with renal syndrome. Nephron 67: 252, 1994.

14. Padula PJ, Edelstein A, Miguel SD, López NM, Rossi CM and Rabinovich RD: Hantavirus pulmonary syndrome outbreak in Argentina: Molecular evidence for person-to-person transmission of Andes virus. Virology 241: 323-330, 1998.

15. Martinez VP, Bellomo C, San Juan J, Pinna D, Forlenza R, Elder M and Padula PJ: Person-to-person transmission of Andes virus. Emerg Infect Dis 11: 1848-1853, 2005.

16. European Centre for Disease Prevention and Control: https:// www.ecdc.europa.eu/en/publications-data/hantavirus-infectionannual-epidemiological-report-2018. Accessed June 25, 2020.

17. Antoine M, Langlois ME, Bres E, Rabeyrin M, Reynes JM and Deeb A: Imported haemorrhagic fever with renal syndrome caused by Dobrava-Belgrade hantavirus in France. Clin Kidney J 14: 1014-1016, 2020.

18. Shirai H, Yashima J, Tojimbara T and Honda K: Thrombotic microangiopathy caused by oral contraceptives in a kidney transplant recipient. Nephrology (Carlton) 21 (Suppl 1): S41-S43, 2016.

19. Douron E, Moriniere B, Matheron S, Girard PM, Gonzalez JP, Hirsch F and McCormick JB: HFRS after a wild rodent bite in the Haute-Savoie- and risk of exposure to Hantaan-like virus in a Paris laboratory. Lancet 1: 676-677, 1984.

20. Mustonen J, Partanen J, Kanerva M, Pietilä K, Vapalahti O, Pasternack A and Vaheri A: Genetic susceptibility to severe course of nephropathia epidemica caused by Puumala hantavirus. Kidney Int 49: 217-221, 1996. 
21. Mäkelä S, Mustonen J, Ala-Houhala I, Hurme M, Partanen J, Vapalahti O, Vaheri A and Pasternack A: Human leukocyte antigen-B8-DR3 is a more important risk factor for severe Puumala hantavirus infection than the tumor necrosis factor-alpha (308) G/A polymorphism. J Infect Dis 186: 843-846, 2002.

22. Paakkala A, Mäkelä S, Hurme M, Partanen J, Huhtala H and Mustonen J: Association of chest radiography findings with hostrelated genetic factors in patients with nephropathia epidemica. Scand J Infect Dis 40: 254-258, 2008.

23. Mustonen J, Partanen J, Kanerva M, Pietilä K, Vapalahti O, Pasternack A and Vaheri A: Association of HLA B27 with benign clinical course of nephropathia epidemica caused by Puumala hantavirus. Scand J Immunol 47: 277-279, 1998.

24. Vaheri A, Henttonen H, Voutilainen L, Mustonen J, Sironen T and Vapalahti O: Hantavirus infections in Europe and their impact on public health. Rev Med Virol 23: 35-49, 2013.

25. Gavrilovskaya IN, Gorbunova EE and Mackow ER: Pathogenic hantaviruses direct the adherence of quiescent platelets to infected endothelial cells. J Virol 84: 4832-4839, 2010.

26. Gavrilovskaya IN, Brown EJ, Ginsberg MH and Mackow ER: Cellular entry of hantaviruses which cause hemorrhagic fever with renal syndrome is mediated by beta3 integrins. J Virol 73 3951-3959, 1999.

27. Krautkramer E, Grouls S, Stein N, Reiser J and Zeier M Pathogenic old word hantaviruses infect renal glomerular and tubular cells and induce disassembling of cell-to-cell contacts. J Virol 85: 9811-9823, 2011.

28. Boehlke C, Hartleben B, Huber T, Hopfer H, Walz G and Neumann-Haefelin E: Hantavirus infection with severe proteinuria and podocyte foot-process effacement. Am J Kidney Dis 64 452-456, 2014

29. Krautkramer E, Zeier M and Plyusnin A: Hantavirus infection: An emerging infectious disease causing acute renal failure. Kidney Int 83: 23-27, 2013.

30. Peebles RS Jr and Graham BS: Viruses, dendritic cells and the lung. Respir Res 2: 245-249, 2001

31. Schonrich G, Rang A, Lutteke N, Raftery MJ, Charbonnel N and Ulrich RG: Hantavirus-induced immunity in rodent reservoirs and humans. Immunol Rev 225: 163-189, 2008

32. Terajima M and Ennis FA: T cells and pathogenesis of hantavirus and cardiopulmonary syndrome and hemorrhagic fever with renal syndrome. Viruses 3: 1059-1073, 2011.

33. Safronetz D, Zivcec M, Lacasse R, Feldmann F, Rosenke R, Long D, Haddock E, Brining D, Gardner D, Feldmann H and Ebihara H: Pathogenesis and host response in Syrian hamsters following intranasal infection with Andes virus. PLoS Pathog 7 : e1002426, 2011.

34. Saksida A, Wraber B and Avsic-Zupanc T: Serum levels of inflammatory and regulatory cytokines in patients with hemorrhagic fever with renal syndrome. BMC Infect Dis 11: 142, 2011

35. Hägele S, Müller A, Nusshag C, Reiser J, Zeier M and Krautkrämer E: Motility of human renal cells is disturbed by infection with pathogenic hantaviruses. BMC Infect Dis 18: 645, 2018.

36. Mustonen J, Mäkelä S, Heli H, Helanterä A, Miettinen M, Partanen J and Pasternack A: Mesangiocapillary glomerulonephritis caused by Puumala hantavirus infection. Nephron 89 402-407, 2001

37. Papadimitriou M: Hantavirus nephropathy. Kidnei Int 48 $887-902,1995$

38. Li XZ, Jin XM and Li H: Semi-thin sections and electron microscopy in epidemic hemorrhagic fever. Trans Harbin Med Univ 3: 43-46, 1984

39. Clement J, Lee APK, Verpooten GA, Laenen L, Vergote V, De Samblanx H, Berneman ZN, Van Ranst M and Maes P: Acute hantavirus infection presenting as haemolytic-uraemic syndrome (HUS): The importance of early clinical diagnosis. Eur J Clin Microbiol Infect Dis 37: 135-140, 2018

40. Gheorghe G, Ceobanu G, Gheorghe F, Bratu OG, Bacalbasa N Bungau S and Diaconu CC: Fever of unknown origin. Rom J Mil Med 123: 213, 2020

41. Hautala N, Kauma H, Vapalahti O, Mähönen SM, Vainio O, Vaheri A and Hautala T: Prospective study on ocular findings in acute Puumala hantavirus infection in hospitalised patients. $\mathrm{Br}$ J Ophthalmol 95: 559-562,2011.

42. McCaughey C and Hart CA: Hantaviruses. J Med Microbiol 49: $587-599,2000$

43. Linderholm M and Elgh F: Clinical characteristics of hantavirus infections on the Eurasian continent. Curr Top Microbiol Immunol 256: 135-151, 2001
44. Kruger DH, Ulrich R and Lundkvist AA: Hantavirus infections and their prevention. Microbes Infect 3: 1129-1144, 2001.

45. Jereb M, Lunacek NK, Kotar T, Saksida A, Petrovec M and Avsic-Zupanc T: Procalcitonin in hantavirus infections. Scand J Clin Lab Invest 71: 287-291, 2011.

46. Outinen TK, Mäkelä SM, Ala-Houhala IO, Huhtala HS, Hurme M, Paakkala AS, Pörsti IH, Syrjänen JT and Mustonen JT: The severity of Puumala hantavirus induced nephropathia epidemica can be better evaluated using plasma interleukin- 6 than C-reactive protein determinations. BMC Infect Dis 10: 132, 2010.

47. Mäkelä S, Mustonen J, Ala-Houhala I, Hurme M, Koivisto AM, Vaheri A and Pasternack A: Urinary excretion of interleukin-6 correlates with proteinuria in acute Puumala hantavirus-induced nephritis. Am J Kidney Dis 43: 809-816, 2004

48. Paakkala A, Mustonen J, Viander M, Huhtala H and Pasternack A Complement activation in nephropathia epidemica caused by Puumala hantavirus. Clin Nephrol 53: 424-431, 2000.

49. Sane J, Laine O, Mäkelä S, Paakkala A, Jarva H, Mustonen J, Vapalahti O, Meri A and Vaheri A: Complement activation in Puumala hantavirus infection correlates with disease severity. Ann Med 44: 468-475, 2012.

50. Laine O, Mäkelä S, Mustonen J, Huhtala H, Szanto T, Vaheri A, Lassila R and Joutsi-Korhonen L: Enhanced thrombin formation and fibrinolysis during acute Puumala hantavirus infection. Thromb Res 126: 154-158, 2010.

51. Wang M,Wang J,Wang T,Li J,HuiL and HaX: Thrombocytopenia as a predictor of severe acute kidney injury in patients with Hantaan virus infections. PLoS One 8: e53236, 2013.

52. Rasche FM, Uhel B, Krüger DH, Karges W, Czock D, Hampl W, Keller F, Meisel H and von Müller L: Thrombocytopenia and acute renal failure in Puumala hantavirus infections. Emerg Infect Dis 10: 420-425, 2004

53. Braun N, Haap M, Overkamp D, Kimmel M, Alscher MD, Lehnert $\mathrm{H}$ and Haas CS: Characterization and outcome following Puumala virus infection: A retrospective analysis of 75 cases. Nephrol Dial Transplant 25: 2997-3003, 2010.

54. Hukic M, Valjevac A, Tulumovic D, Numanovic F and Heyman P: Pathogenicity and virulence of the present hantaviruses in Bosnia and Herzegovina: The impact on renal function. Eur J Clin Microbiol Infect Dis 30: 381-385, 2011

55. Clement J, Maes P, Lagrou K, Van Ranst M and Lameire N: A unifying hypothesis and a single name for a complex globally emerging infection: Hantavirus disease. Eur J Clin Microbiol Infect Dis 31: 1-5, 2012

56. Mäkelä S, Kokkonen L, Ala-Houhala I, Groundstroem K, Harmoinen A, Huhtala H, Hurme M, Paakkala A, Porsti I, Virtanen V, et al: More than half of the patients with acute Puumala hantavirus infection have abnormal cardiac findings. Scand J Infect Dis 41: 57-62, 2009.

57. Mustonen J, Brummer-Korvenkontio M, Hedman K, Pasternack A, Pietilä K and Vaheri A: Nephropathia epidemica in Finland: A retrospective study of 126 cases. Scand J Infect Dis 26: 7-13, 1994.

58. Bergmann F, Krone B, Bleich S, Prange H and Paulus W Encephalitis due to a hantavirus infection. J Infect 45: 58-59, 2002

59. Ahlm C, Lindén C, Linderholm M, Alexeyev OA, Billhedent J, Elgh F, Fagerlund M, Zetterlund B and Settergren B: Central nervous system and ophthalmic involvement in nephropathia epidemica (European type of haemorrhagic fever with renal syndrome). J Infect 36: 149-155, 1998.

60. Hautala T, Mähönen SM, Sironen T, Hautala N, Pääkkö E, Karttunen A, Salmela PI, Ilonen J, Vainio O, Glumoff V, et al: Central nervous system-related symptoms and findings are common in acute Puumala hantavirus infection. Ann Med 42: 344-351, 2010.

61. Launes J and Hautanen A: Nephropathia epidemica encephalitis. Acta Neurol Scand 78: 234-235, 1988.

62. Alexeyev OA and Morozov VG: Neurological manifestations of hemorrhagic fever with renal syndrome caused by Puumala virus: Review of 811 cases. Clin Infect Dis 20: 255-258, 1995.

63. Cerar D, Avsic-Zuapanc T, Jereb M and Strle F: Case report: Severe neurological manifestation of Dobrava hantavirus infection. J Med Virol 79: 1841-1843, 2007.

64. Settergren B, Boman J, Linderholm M, Wiström J, Hägg E and Arvidsson PA: A case of nephropathia epidemica associated with panhypopituitarism and nephrotic syndrome. Nephron 61: 234-235, 1992 .

65. Kilit TP, Kilit C and Erarslan S: A rare cause of acute pancreatitis: Hantavirus infection. Acta Gastroenterol Belg 80: 59-61, 2017. 
66. Hoier S, Aberle SW, Langner C, Schnedl W, Högenauer C, Reisinger EC, Krejs GJ and Krause R: Puumala virus RNA in patient with multiorgan failure. Emerg Infect Dis 12: 356-357, 2006.

67. Miettinen MH, Makela SM, Ala-Houhala IO, Huhtala HS Koobi T, Vaheri AI, Pasternack AI, Porsti IH and Mustonen JT: Tubular proteinuria and glomerular filtration 6 years after Puumala hantavirus-induced acute interstitial nephritis. Nephron Clin Pract 112: c115-c120, 2009.

68. Miettinen M, Mäkelä S, Haapala M, Helanterä A, Helin H, Vänttinen T and Mustonen J: Glomerulonephritis emerging shortly after Puumala hantavirus infection: A report of 7 patients. Clin Nephrol 75: 550-556, 2011.

69. Tulumovic D, Imamovic G, Mesic E, Hukic M, Tulumovic A, Imamovic A and Zerem E: Comparison of the effects of Puumala and Dobrava viruses on early and long-term renal outcomes in patients with haemorrhagic fever with renal syndrome. Nephrology (Carlton) 15: 340-343, 2010.

70. Mäkelä S, Jaatinen P, Miettinen M, Salmi J, Ala-Houhala I, Huhtala H,Hurme M,Pörsti I, Vaheri A and Mustonen J: Hormonal deficiencies during and after Puumala hantavirus infection. Eur J Clin Microbiol Infect Dis 29: 705-713, 2010.

71. Pekic S, Cvijovic G, Stojanovic M, Kendereski A, Micic D and Popovic V: Hypopituitarism as a late complication of hemorrhagic fever. Endocrine 26: 79-82, 2005.

72. Stojanovic M, Pekic S, Cvijovic G, Miljic D, Doknic M, Nikolic-Djurovic M, Micic D, Hrvacevic R, Nesic V and Popovic V: High risk of hypopituitarism in patients who recovered from hemorrhagic fever with renal syndrome. J Clin Endocrinol Metab 93: 2722-2728, 2008

73. Miettinen MH, Mäkelä SM, Ala-Houhala IO, Huhtala HS, Kööbi T, Vaheri AI, Pasternack AI, Pörsti IH and Mustonen JT: Ten-year prognosis of Puumala hantavirus-induced acute interstitial nephritis. Kidney Int 69: 2043-2048, 2006.

74. Plyusnin A, Hörling J, Kanerva M, Mustonen J, Cheng Y, Partanen J, Vapalahti O, Kukkonen SK, Niemimaa J, Henttonen $\mathrm{H}$, et al: Puumala hantavirus genome in patients with nephropathia epidemica: Correlation of PCR positivity with HLA haplotype and link to viral sequences in local rodents. J Clin Microbiol 35: 1090-1096, 1997.

75. Evander M, Eriksson I, Pettersson L, Juto P, Ahlm C, Olsson GE, Bucht $\mathrm{G}$ and Allard A: Puumala hantavirus viremia diagnosed by real-time reverse transcriptase PCR using samples from patients with hemorrhagic fever and renal syndrome. J Clin Microbiol 45 2491-2497, 2007

76. Saksida A, Duh D, Korva M and Avsic-Zupanc T: Dobrava virus RNA load in patients who have hemorrhagic fever with renal syndrome. J Infect Dis 197: 681-685, 2008.
77. Xiao R, Yang S, Koster F, Ye C, Stidley C and Hjelle B: Sin Nombre viral RNA load in patients with hantavirus cardiopulmonary syndrome. J Infect Dis 194: 1403-1409, 2006.

78. Laslo CL, Bacalbasa N, Ana MAS, Carsote M, Bungau S, Rus M, Bratu OG and Diaconu CC: New oral anticoagulants-possible extension to other indications (Review). Exp Ther Med 20: 2401-2405, 2020.

79. Outinen TK, Mäkelä S, Clement J, Paakkala A, Pörsti I and Mustonen J: Community acquired severe acute kidney injury caused by hantavirus-induced hemorrhagic fever with renal syndrome has a favorable outcome. Nephron 130: 182-190, 2015.

80. Huggins JW: Prospects for treatment of viral hemorrhagic fevers with ribavirin, a broad-spectrum antiviral drug. Rev Infect Dis 11 (Suppl 4): S750-S761, 1989.

81. Huggins JW, Hsiang CM, Cosgriff TM, Guang MY, Smith JI, Wu ZO, LeDuc JW, Zheng ZM, Meegan JM, Wang QN, et al: Prospective, double-blind, concurrent, placebo-controlled clinical trial of intravenous ribavirin therapy of hemorrhagic fever with renal syndrome. J Infect Dis 164: 1119-1127, 1991.

82. Rusnak JM, Byrne WR, Chung KN, Gibbs PH, Kim TT, Boudreau EF, Cosgriff T, Pittman P, Kim KY, Erlichman MS, et al: Experience with intravenous ribavirin in the treatment of hemorrhagic fever with renal syndrome in Korea. Antiviral Res 81: 68-76, 2009.

83. Antonen J, Leppänen I, Tenhunen J, Arvola P, Mäkelä S, Vaheri A and Mustonen J: A severe case of Puumala hantavirus infection successfully treated with bradykinin receptor antagonist icatibant. Scand J Infect Dis 45: 494-496, 2013.

84. Sironen T, Sane J, Lokki ML, Meri S, Andersson LC, Hautala T, Kauma H, Vuorinen S, Rasmuson J, Evander M, et al: Fatal Puumala hantavirus disease: Involvement of complement activation and vascular leakage in the pathobiology. Open Forum Infect Dis 4: ofx229, 2017.

85. Tapia M, Mansilla C, Jose TM and Vera M: Hantavirus pulmonary syndrome, clinical experience in diagnosis and treatment. Hospital Coyhaique-Chile. Rev Chil Infect 17: 258-269, 2000.

86. Vial PA, Valdivieso F, Ferres M, Riquelme R, Rioseco ML, Calvo M, Castillo C, Díaz R, Scholz L, Cuiza A, et al: High-dose intravenous methylprednisolone for hantavirus cardiopulmonary syndrome in Chile: A double-blind, randomized controlled clinical trial. Clin Infect Dis 57: 943-951, 2013.

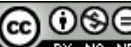

This work is licensed under a Creative Commons

Attribution-NonCommercial-NoDerivatives 4.0 International (CC BY-NC-ND 4.0) License. 